Oncol Biol Phys, 61(4), 1123-1128.

6. Toya R., Matsuyama T., Saito T. và cộng sứ. (2019). Impact of hybrid FDG-PET/CT on gross tumor volume definition of cervical esophageal cancer: reducing interobserver variation. Journal of Radiation Research, 60(3), 348-352.
7. Vesprini D, Ung $Y$, Dinniwell $R$ et al (2008) Improving observer variability in target delineation for gastro-oesophageal cancer-the role of $18 \mathrm{~F}$ fluoro-2-deoxy-D-glucosepositron emission tomogra- phy/computed tomography. Clin Oncol 20:631-638.

\title{
ĐÁNH GIÁ TÌNH TRANG NHIỄM KHUẨN VẾT MỔ VÀ MộT SỐ YẾU Tố LIÊN QUAN NGƯỜI BÊNNH PHẪU THUÂT ỐNG TIỂU HÓA TẠI BÊ̂NH VIỆN THANH NHÀN
}

\author{
Nguyễn Thị Bích Ngọc*, Nguyễn Hoàng**, Trương Quang Trung**
}

\section{TÓM TẮT}

Mục tiêu: Nghiên cứu nhằm 2 muc tiêu, bao gồm mô tả đặc điểm nhiểm khuẩn vết mố của người bệnh phẫu thuật ống tiêu hóa tại Bệnh viện Thanh Nhàn và phân tích một số yếu tố liên quan đến nhiễm khuẩn vết mổ người bênh phẫu thuật ống tiêu hóa từ tháng $7 / 2020$ đến tháng 12/2020. Đối tượng và phương pháp nghiên cứu: Nghiên cứu sử dựng phương pháp quan sát mô tả, tiến cứu trên những bệnh nhân phẫu thuật tiêu hóa tại khoa Ngoại Tổng hợp Bệnh viện Thanh Nhàn, trong thời gian nghiên cứu từ tháng $7 / 2020$ đến hết tháng 12/2020. Kết quả: Tuổi trung bình của người bệnh trong nghiên cứu này là $48,56 \pm$ $22,45,46,1 \%$ bệnh nhân không có tiền sử bếnh lý kèm theo. Trong 228 ca mổ, có 136 bệnh nhân không đặt dẫn lưu sau mổ $(59,6 \%)$, có 170 ca mổ nội soi chiếm 74,6\%; có 58 ca mổ mở chiếm tỉ lệ 25,4\%. Loại phẫu thuật sạch- nhiễm với số lượng bệnh nhân lớn nhất là 134 bểnh nhân $(58,8 \%)$. Chỉ số nguy cơ nhiếm trùng vết mổ được sử dụng theo hệ thống NNIS: $41(18,0 \%)$ bệnh nhân có nguy cơ NKViM cao và rất cao. Tình trạng nhiểm trùng sau mổ có mối tương quan với một số yếu tố: tiên sử bệnh kèm theo; cách thức phẫu thuật; thời gian phẫu thuật; đă̆t dần lưu sau mổ. Vết mố có phân loại sạch - nhiếm, nhiếm, bẩn có nguy cơ nhiễm trùng vêt mổ cao hơn vết mổ có phân loại sach. Kết luân: Tỷ lệ bệnh nhân NKVM không khác biệt theo tuổi, BMI, và cách thức phẫu thuật. Chỉ số nguy cơ NKVM và tî lê NKVM đều có mối tươning quan với tiền sử bệnh lý kèm theo, phân loại phẫu thuật, cách thức phẫu thuật, thời gian phẫu thuật, tình trạng đặt dẫn lưu sau mổ, ngoài ra chỉ số nguy cơ NKVM̀ còn có mối tương quan tuổi, phân loại ASA, hình thức phẫu thuật. Thời gian nằm điều trị sau mổ của nhóm bệnh nhân có nhiêm trùng vết mổ dài hơn nhiều so với nhóm bệnh nhân không có nhiếm trùng vết mổ. Từ khóa: Nhiễm khuẩn vêt mổ; Phẫu thuật ống tiêu hóa.

\footnotetext{
*Bệnh viện Thanh Nhàn

**Dai hoc Y Hà Nối

Chịu trách nhiệm chính: Nguyễn Thị Bích Ngọc

Email: ngocnguyenbich3110@gmail.com

Ngày nhận bài: 6.7.2021

Ngày phản biện khoa học: 31.8.2021

Ngày duyệt bài: 9.9.2021
}

\section{SUMMARY \\ EVALUATION OF SURGICAL SITE INFECTION AND FACTORS RELATED TO PATIENTS UNDER- GOING GASTROINTESTINAL SURGERY AT THANH NHAN HOSPITAL}

Purpose: The study aimed to describe the characteristics of surgical site infection (SSI) of patients undergoing gastrointestinal surgery at Thanh Nhan Hospital and analyzing some factors related to surgical site infection. gastrointestinal surgery from July 2020 to December 2020. Material and methods: The study conducted descriptive and prospective observational methods on gastrointestinal surgery patients at the Department of General Surgery, Thanh Nhan Hospital, during the study period from July 2020 to July 2020. end of December 2020. Results: The mean age of patients in this study was $48.56 \pm 22.45,46.1 \%$ of patients had no history of comorbidities. In 228 surgeries, there were 136 patients without postoperative drainage $(59.6 \%), 170$ laparoscopic surgeries, accounting for $74.6 \%$; there were 58 open surgeries, accounting for $25.4 \%$. Cleancontaminated surgery with the largest number of patients was 134 patients $(58.8 \%)$. The risk index of surgical site infection used according to the NNIS system: $41(18.0 \%)$ patients were at high and very high risk of surgical site infection. Postoperative infection is correlated with a number of factors: history of comorbidities; surgical procedure; surgery time; Postoperative drainage placement. Incisions classified as clean - infected, contaminated, dirty have a higher risk of wound infection than incisions with clean classification. Conclusion: The percentage of patients with surgical site infection did not differ according to age, BMI, and surgical method. The risk index of surgical site infection and the rate of UTI are correlated with accompanying medical history, surgical classification, surgical method, surgical time, postoperative drainage status, in addition. Risk index of surgical site infection also correlates with age, ASA classification, type of surgery. The duration of postoperative treatment of the group of patients with surgical site infection was much longer than that of the group of patients without surgical site infection.

Keywords: Surgical site infection; SSI; Gastrointestinal surgery. 


\section{I. ĐẶT VẤN ĐỀ}

Nhiễm khuẩn bênh viện (NKBV) đang trở thành một trong những thách thức và là mối quan tâm hàng đầu tại Việt Nam cũng như trên toàn thễ giới. Tại Việt Nam, có nhiều loại nhiễm khuẩn bệnh viện, trong đó nhiễm khuẩn vết mổ (NKVM) là môt trong bốn loại nhiễm khuẩn bênh viện phổ biến nhất hiện nay, đứng hàng thứ hai trong nhiếm khuẩn Bệnh viện, sau nhiễm khuẩn hô hấp [1]. Trong các phẫu thuật ngoại khoa, phẫu thuật tiêu hóa có nguy cơ nhiễm khuẩn vết mổ cao hơn vì khi can thiệp vào đường tiêu hóa sẽ tăng nguy cơ phơi nhiếm với vi khuẩn và theo phân loại vết mổ thì phẫu thuật tiêu hóa chủ yễu là các phẫu thuật nhiễm và phẫu thuât bẩn, dẫn đến khả năng phơi nhiễm cao $[2,3]$. Nguyên nhân gây nhiểm khuẩn vết mổ là do vi khuẩn, vi rút, nấm và ký sinh trùng; trong đó nguyên nhân do vi khuẩn là phổ biến nhất $[4,5]$. Việc xâm nhập, phát triển và gây bệnh của các nguyên nhẩn gây nhiễm khuẩn vết mổ phụ thuộc vào 4 nhóm yếu tố nguy cơ sau: yếu tố môi trường, yếu tố phẫu thuật, yếu tố người bệnh và yếu tố vi khuẩn [2]. Các yếu tố này tác động qua lại, đan xen với nhau làm tăng nguy cơ nhiểm khuẩn vết mổ. Bệnh viện Thanh Nhàn với quy mô hơn 1000 giường bệnh khám, điều trị cũng như thực hiện các ca phẫu thuật ngày càng đông cho người bệnh, điều này dẫn đến công tác chăm sóc sau mố phải được quan tâm một cách đầy đủ và toàn diên hơn.

\section{II. ĐỐI TƯợNG VÀ PHƯƠNG PHÁP NGHIÊN CứU}

2.1 Thiết kế nghiên cứu. Sử dụng phương pháp quan sát mô tả, tiến cứu trên những bênh nhân phẫu thuật tiêu hóa tại khoa Ngoại Tổng hợp Bệnh viện Thanh Nhàn, trong thời gian nghiên cứu từ tháng $7 / 2020$ đến hết tháng 12/2020. Nghiên cứu sử dưng phương pháp chọn mấu có chủ đích, chọn mẫu theo tiêu chuẩn và chọn liên tục.

\subsection{Kỹ thuật và công cụ nghiên cứu}

Phương pháp thu thập số liệu: Thu thập thông tin về tình trạng NKVM và các yếu tố liển quan từ hồ sơ bệnh án.

Công cụ thu thập số liệu: Bệnh án nghiên cứu gồm 3 phần: phần 1 là đặc điểm của đối tượng nghiên cứu; phần 2 là thồng tin trước và trong phẫu thuật; phần 3 là tình trạng sau phẫu thuật.

Bộ phiếu điều tra: Bộ phiếu giám sát nghiên cứu NKVM được thiết kế sẵn dựa trên các khuyến các Trung tâm phòng ngựa kiểm soát bệnh tật Hoa Kỳ và các hướng dẩn của bộ y tế, [3]; bộ phiếu được đánh giá về tính phù hợp qua giám sát thử 1 tháng trước khi bắt đầu nghiên cứu.

Việc thu thập số liệu được tiến hành theo trình tự sau: Lập danh sách bệnh nhân nghiên cứu; Căn cứ và̀o danh sách bệnh nhân nghiên cứu tiến hành thăm khám lâm sàng, cận lâm sàng, lấy mẫu xét nghiệm vi sinh nhằm xác định NKVM và nguyên nhẩn NKVM nếu có nhiễm khuẩn; Những thông tin cần thiết được điền vào bệnh án nghiên cứu gồm: Hành chính, tình trạng nhiễm khuẩn khi nhập viện, thông tin liên quan tới PT, kết quả xét nghiệm vi sinh, kháng sinh sử dụng ở bệnh nhân.

\section{KẾT QUẢ NGHIÊN CỨU \\ Đặc điểm chung của người bệnh}

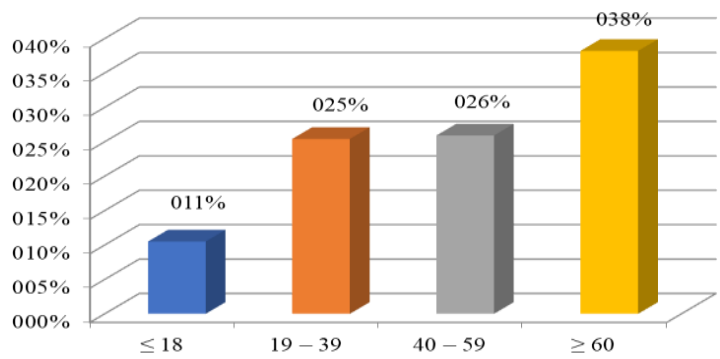

Biểu đồ 1. Tỉ lệ phân bố tuổi theo nhóm

Tuổi trung bình của người bệnh trong nghiên cứu này là 48,56 $\pm 22,45$ tuổi.

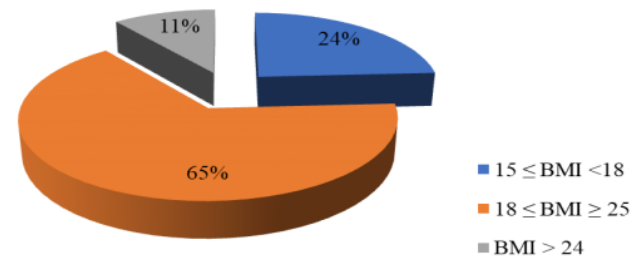

Biểu đồ 2. Tình trạng BMI của bệnh nhân tham gia nghiên cứu

Tình trạng thể lực của người bệnh thu thập thông qua việc sử dụng chỉ số BMI: 55 (24,1\%) bệnh nhân có thể trạng gầy/ suy dinh dưỡng; $149(65,4 \%)$ bệnh nhân có thể trạng bình thường; 24 (10,5\%) bệnh nhân có thể trạng béo.

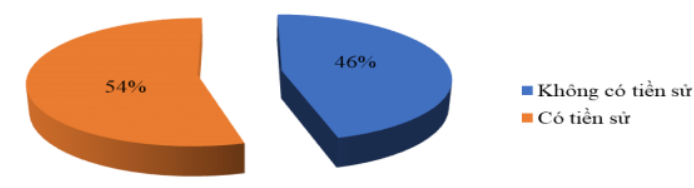

Biểu đồ 3. Tiền sử bênh lý kèm theo của bệnh nhân khi vào viện 
Tỉ lệ bệnh nhân có tiền sử bệnh lý kèm theo khi vào viện là tương đương nhau. Có 105 $(46,1 \%)$ bệnh nhân không có tiền sử bệnh lý kèm theo; $123(53,9 \%)$ bệnh nhân có tiền sử bệnh lý mắc bệnh lý kèm theo.

Bảng 1. Loại phấu thuật của BN nghiên cứu

\begin{tabular}{|c|c|c|}
\hline Loại phâu thuật & n & Tỷ lệ \% \\
\hline $\begin{array}{c}\text { Phâu thuật ống mật, gan } \\
\text { hoặc tuyến tụy }\end{array}$ & 56 & $24,6 \%$ \\
\hline Phâu thuật ruột non & 1 & $0,4 \%$ \\
\hline $\begin{array}{l}\text { Phâu thuật đại tràng, trực } \\
\text { tràng }\end{array}$ & 23 & $10,1 \%$ \\
\hline Phâu thuật dạ dày, tá tràng & 33 & $14,5 \%$ \\
\hline Phâu thuật ruột thừa & 115 & $50,4 \%$ \\
\hline Tống & 228 & $100 \%$ \\
\hline
\end{tabular}

Các yếu tố nguy cơ phầu thuật

Bảng 2. Các yếu tố nguy cơ phẫu thuật

\begin{tabular}{|c|c|c|c|}
\hline \multicolumn{2}{|c|}{ Đăc điếm } & N (228) & Tỉ lệ (\%) \\
\hline \multirow{2}{*}{$\begin{array}{c}\text { Thời gian } \\
\text { mổ }\end{array}$} & $\leq 120$ phút & 172 & $75,4 \%$ \\
\hline & $>120$ phút & 56 & $24,6 \%$ \\
\hline \multirow{2}{*}{$\begin{array}{c}\text { Độ dài vết } \\
\text { mổ }\end{array}$} & $\leq 10 \mathrm{~cm}$ & 183 & $80,3 \%$ \\
\hline & $>10 \mathrm{~cm}$ & 45 & $19,7 \%$ \\
\hline \multirow{2}{*}{\begin{tabular}{|c|} 
Tình trang \\
dẫn lưư \\
sau mổ
\end{tabular}} & Có & 92 & $40,4 \%$ \\
\hline & Không & 136 & $59,6 \%$ \\
\hline \multirow{2}{*}{$\begin{array}{c}\text { Hình thức } \\
\text { mổ }\end{array}$} & $\begin{array}{c}\text { Mố có kế } \\
\text { hoach }\end{array}$ & 108 & $47,4 \%$ \\
\hline & Mố cấp cứu & 120 & $52,6 \%$ \\
\hline \multirow{3}{*}{$\begin{array}{l}\text { Cách thức } \\
\text { phẫu thuật }\end{array}$} & Mố mở & 58 & $25,4 \%$ \\
\hline & Mố nội soi & 170 & $74,6 \%$ \\
\hline & Sạch & 02 & $0,9 \%$ \\
\hline \multirow{3}{*}{$\begin{array}{l}\text { Loại phẫu } \\
\text { thuật }\end{array}$} & Sạch- nhiêm & 134 & $58,8 \%$ \\
\hline & Nhiếm & 64 & $28,1 \%$ \\
\hline & Bấn & 28 & $12,3 \%$ \\
\hline
\end{tabular}

Thời gian mổ: Trong $228 \mathrm{ca}$ mố, cả mố mở và mổ nội soi, mổ cấp cứu và mổ phiên thời gian trung bình là 102,28 $\pm 57,57$ phút.

Độ dài vết mổ: Bệnh nhân có chiều dài vết mổ < $10 \mathrm{~cm}$ là 183 bệnh nhân (80,3\%); bệnh nhân có chiều dài vết mổ $\geq 10 \mathrm{~cm}$ là 45 bệnh nhân $(19,7 \%)$.

Tình trạng dẫn lưu: Trong 228 ca mổ, có 136 bệnh nhân không đặt dẫn lưu sau mổ $(59,6 \%)$ và 92 bệnh nhân có đặt dẫn lưu sau mổ (40,4\%).

Hình thức mổ: Hình thức mổ trong nghiên cứu được định nghĩa là mổ cấp cứu và mổ phiên, liên quan đến công tác chuẩn bị trước mổ. Trong 228 ca mổ có 108 ca mổ phiên chiếm tỉ lệ $47,4 \%$ và 120 ca mổ cấp cứu chiếm tỉ lệ 52,6\%.

Cách thức phẫu thuật: là việc sử dụng phương pháp mổ mở hoặc mổ nội soi. Các trường hợp kết hợp mổ nội soi và mổ mở được xác định thành mổ mở. Trong 228 ca mổ, có 170 ca mổ nội soi chiếm $74,6 \%$; có 58 ca mổ mở chiếm tỉ lệ $25,4 \%$. Số bệnh nhân mổ nội soi gấp 3 lần số bệnh nhân mổ mở.

Loại phẫu thuật: Loại phẫu thuật sạchnhiễm với số lượng bệnh nhân lớn nhất là 134 bệnh nhân $(58,8 \%)$; thấp nhất là phẫu thuât sạch với số bệnh nhân là $02(0,9 \%)$; loại PT bẩn là $28(12,3 \%)$.

\section{Nguy cơ nhiễm trùng vết mổ (NNIS)}

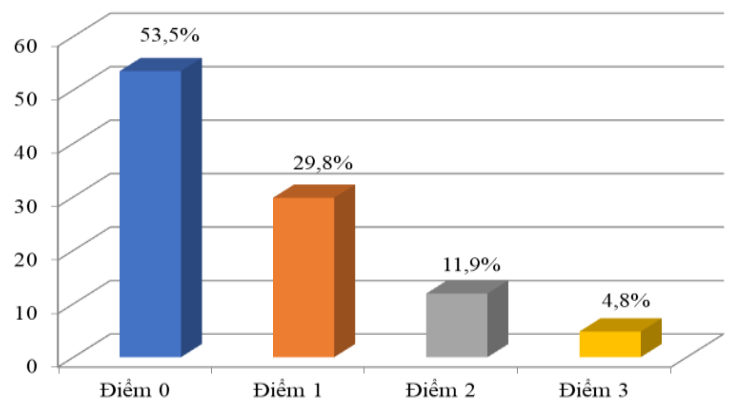

Biểu đồ 4. Sự phân bố chỉ số nguy cơ NNIS trong nghiên cứu

Chỉ số nguy cơ nhiểm trùng vết mổ được sử dụng theo hệ thống NNIS: 187 (81,3\%) bệnh nhân không có NKVM và nguy cơ NKVM rất thấp; $41(18,0 \%)$ bệnh nhân có nguy cơ NKVM cao và rất cao.

Kết quả chăm sóc vết mổ. Kết quả chăm sóc sau mổ: Trong số 228 bệnh nhân tham gia nghiên cứu, có $217(95,2 \%)$ bệnh nhân không có biểu hiện của nhiễm trùng vết mổ. Chỉ có 11 $(4,8 \%)$ bệnh nhân có biểu hiện nhiễm trùng ở các mức độ khác nhau. Trong đó có $08(72,7 \%)$ trường hợp có nhiễm trùng vết mổ nông, 03 $(27,3 \%)$ trường hợp có nhiễm trùng vết mổ sâu, không có trường hợp nào có nhiễm trùng khoang/cơ quan. 04 bệnh nhân nuôi cây vi khuẩn thì có 02 bệnh nhẩn dương tính; trong đó có 3 loại vi khuẩn: E.coli, Klebsieblla, Enterococus.

Các hoạt động chăm sóc sau mổ. Những hoạt động chăm sóc sau mổ ở tất cả các bệnh nhẩn sau khi mổ về đều được thực hiên hoàn toàn và đầy đủ theo đúng quy trình được quy định tại khoa Ngoại Tổng hợp- BV Thanh Nhàn

Mối tượng quan giữa các yếu tố trong nghiên cứu. Chăm sóc sau mổ (tình trạng nhiễm trùng sau mổ) có mối tương quan với một số yếu tố và có ý nghĩa thống kê $\mathrm{p}<0,05$ như: tiên sử bệnh kèm theo (bệnh nhân có tiền sử bênh lý kèm theo có nguy cơ nhiễm trùng vết mổ cao hơn bệnh nhân không có tiền sử bệnh lý kèm theo); cách thức phẫu thuật (bệnh nhẩn mổ mở có nguy cơ nhiễm trùng cao hơn so với bệnh nhân mổ nội soi); thời gian phẫu thuật (trên 120 
phút có nguy cơ nhiễm trùng cao hơn so với bệnh nhân có thời gian phẫu thuật $\leq 120$ phút); đặt dẫn lưu sau mổ (vết mổ có đặt dẫn lưu sau mổ có nguy cơ nhiễm trùng vết mổ cao so với vết mổ không đăt dẫn lưu sau mổ).

Vết mổ có phân loại sạch - nhiễm, nhiễm, bẩn có nguy cơ nhiễm trùng vết mổ cao hơn vết mổ có phân loại sạch.

\section{BÀN LUÂN}

Triệu chứng lâm sàng và cận lâm sàng của bệnh nhân nghiên cứu. Độ tuổi trung bình của $\mathrm{BN}$ trong nghiên cứu của chúng tôi là $48,56 \pm 22,45$ Tỷ lệ NKVM có xu hướng tăng theo nhóm tuổi trong nghiên cứu, với nhóm tuổi lớn hơn hoăc bằng 60 tuổi có tỷ lệ NKVM cao nhất $(81,8 \%)$. Tác giả Lê Minh Luẩn cũng cho thấy tỷ lệ NKVM có xu hướng tăng theo nhóm tuổi như trên, tuy nhiên sự khác biệt giữa tỷ lệ có NKVM và không NKVM ở các nhóm tuổi là không có ý nghĩa thống kê với p > 0,05 [6].

Tỷ lệ loại PT trong nghiên cứu của chúng tôi như sau: cao nhất là $\mathrm{PT}$ ruột thừa và biến chứng của ruột thừa $(50,4 \%)$. Tỷ lệ NKVM giữa các loại PT trong nghiên cứu của chúng tôi khác so với tác giả khác cũng có thể lý giải do thời điểm, địa điểm nghiên cứu của chúng tôi và tác giả trên là khác nhau hoặc có thể do tình trạng bệnh lý của hệ tiêu hóa trong nghiên cứu của chúng tôi cũng khác với các tác giả $[6,7]$.

Theo Bộ $Y$ tế thì một trong những yếu tố nguy cơ gây NKVM là thời gian PT, thời gian PT càng dài thì nguy cơ NKVM càng cao [2]. Trong nghiên cứu của chúng tôi, tỉ lệ bệnh nhân NKVM có thời gian phẫu thuật > 120 phút là $91 \%$. Thời gian PT là yếu tố liên quan đến tỷ lệ NKVM, thời gian PT càng dài thì càng tăng tỷ lệ NK. Trong đó, $B N$ được mổ cấp cứu chiếm $52,6 \%$, và mổ có kế hoạch chiếm 47,4\%. Trong đó, tỉ lệ NKVM đối với bểnh nhân trong nhóm nghiên cứu có tỉ lệ mổ có kế hoạch $(72,7 \%)$ lại lớn hơn mổ cấp cứu $(27,3 \%)$. Có thể lý giải về những bệnh nhân được PT theo hình thức mổ có kế hoạch trong nghiên cứu của chúng tôi chiếm tỷ lệ cao hơn là do bệnh nhân vào PT trong tình trạng bệnh lý mắc các bệnh lý kèm theo $(81,8 \%)$, thể trạng người bênh trước phẫu thuật đa phần không tốt

Nguy cơ nhiểm trùng vết mổ. Trong thời gian nghiên cứu từ tháng $7 / 2020$ đến tháng 12/2020, chỉ số nguy cơ nhiễm trùng vết mổ của bệnh nhân theo hệ thống NNIS theo điểm chạy từ $0-3$. Kết quả của mối tương quan NKVM và nguy cơ theo hề thống NNIS trong nghiên cứu này cho thấy khả năng NKVM tăng tỉ lệ thuận với chỉ số NNIS.
Chỉ số nguy cơ nhiễm khuẩn này có mối tương quan với tuổi của người bệnh ( tuổi càng cao, bệnh nhân càng có nguy có NKVM càng cao) và tiền sử bệnh lý kèm theo (có tiền sử phẫu thuật trước đó, tiền sử bệnh tim mạch, ...) những bệnh này góp phần làm tăng nguy cơ nhiễm trùng vết mổ.

Chăm sóc và kết quả chăm sóc NKVM. Tất cả bệnh nhân nhiễm khuẩn vết mổ đều được thay băng vết mổ hàng ngày với số lần thay băng tùy thuộc vào mức độ chảy dịch, mủ nhiều hay ít của vết mổ.

Trong nhóm bệnh nhân nghiên cứu, tỉ lệ NKVM nông chiếm $72,7 \%$; và NKVM sâu chiếm $27,3 \%$. Chính vì thế, trước tiên cần phân loại mức độ NKVM để áp dụng kỹ thuật thay băng cho phù hợp: nặn dịch vết mổ, thay băng với những vết mổ tấy đỏ, không có mủ; cắt chỉ cách quãng hoặc toàn bộ, nhét gạc tẩm Betadine vào đáy vết mổ với những vết mổ nhiễm khuẩn rộng, vết mổ có nhiều dịch và có mủ; nếu vết mổ chảy nhiều dịch, mủ , vết mổ nhiễm khuẩn sâu có thể sử dụng biện pháp đặt dẫn lưu tại vết mổ hút liên tục; khâu da thì 2 đối với những vết mổ cắt chỉ sớm, khi vết mổ khô, sạch, lên tổ chức hạt.

Nghiên cứu của chúng tôi cũng cho thấy đa phần bệnh nhân NKVM có sử dụng KSDP trước mổ chiếm $81,8 \%$. Ngoài kháng sinh dự phòng trước phẫu thuật thì trong nghiên cứu của chúng tôi cũng cho thấy $100 \%$ bệnh nhân được sử dụng kháng sinh điều trị khi có biểu hiện nhiếm khuẩn vết mổ và có những bênh nhân phải kết hợp 2 đến 3 loại kháng sinh để tiêu diệt tác nhân gầy bệnh.

Ngoài ra, kết quả chăm sóc và điều trị còn dựa vào thời gian người bệnh nằm viện sau mổ dài hay ngắn. Điều này sẽ làm ảnh hưởng đến thể trạng, tinh thần và kinh tế của bệnh nhân và cũng là một trong những yếu tố gây quá tải cho bệnh viện do người bệnh nằm lâu.

Tuy nhiên, phương pháp tốt nhất của chăm sóc và điều trị NKVM chính là dự phòng vết mổ nhiễm khuẩn để là giảm tỷ lệ NKVM.

\section{KẾT LUÂN}

Tỷ lệ bệnh nhân NKVM trong thời gian nghiên cứu từ tháng $7 / 2020$ đến hết tháng 12/2020 chiếm 4,8\%: NKVM nông (72,7\%), NKVM sâu $(27,3 \%$, ) không có NKVM các khoang/ cơ quan. Tỷ lệ này không khác biệt theo tuổi, $B M I$, và cách thức phẫu thuật. Tỷ lệ nhiễm khuẩn cao nhất trong nhóm bệnh nhân có phẫu thuật đại, trực tràng $(81,8 \%)$.

Chỉ số nguy cơ NKVM và tỉ lệ NKVM đều có 
mối tương quan với tiền sử bệnh lý kèm theo, phân loaii phẫu thuật, cách thức phẫu thuật, thời gian phẫu thuật, tình trạng đặt dẫn lưu sau mổ, ngoài ra chỉ sổ nguy cơ NKVM còn có mối tương quan tuổi, phân loại ASA, hình thức phẫu thuật.

Thời gian nằm điều trị sau mổ của nhóm bệnh nhân có nhiễm trùng vết mổ $(20,82 \pm 5,82$ ngày) dài hơn nhiều so với nhóm bệnh nhân không có nhiễm trùng vết mổ $(8,81 \pm 4,35$ ngày).

\section{TÀI LIỆU THAM KHẢO}

1. Bộ Y tế (2016), Quyết định số 1886/QĐ-BYT phê duyệ̂t "Kể hoạch hành động quốc gia vể kiểm soát nhiếm khuẩn trong các cơ sở khám bệnh, chữa bệnh giai đoạn 2016 - 2020".

2. Bộ Y tế (2012), "Hướng dẫn phòng ngừa nhiễm khuẩn vết mổ", Ban hành kèm theo Quyết định số: 3671/Qð -BYT ngày 27 tháng 9 năăm 2012 của Bộ Y tế.

3. Nguyến Quốc Anh, Nguyến Viêtt Hùng và Phạm Ngọc Trường (2012), "Tỷ lệ mới mắc và yếu tố nguy cơ nhiễm khuẩn vết mổ tại một số bệnh viện của Việt Nam, 2009 - 2010", Tạp chí Y học thực hành, $\mathbf{8 3 0 ( 7 )}$, tr. 28-32.

4. Meyer E., Schwab F., Gastmeier P. và các cộng sự." (2006), "Surveillance of antimicrobial use and antimicrobial resistance in German intensive care units (SARI): a summary of the data from 2001 through 2004", Infection, 34(6), tr. 303-9.

5. World Health Organization (2009), Prevention of hospital acquired, A practical guide 2 nd edition, Geneva, Switzerland.

6. Lê Minh Luân (2006), "Nghiên cứu sử dụng kháng sinh dự phông và một sỗ yếu tố nguy cớ nhiễm khuẩn vết mổ trong phẫu thuật tiểu hóa bệnh viện Việt Đức Hà Nội", Đề tài thạc sĩ, Trường đại họ Y Y Hà Nội.

7. Nguyễn Viêt Hùng và Nguyễn Quốc Anh (2010), "Nhận xét vể tỷ lệ mắc, yếu tố nguy cớ, tác nhân gây bệnh và hậu quả của nhiễm khuẩn vết mổ tại một số bệnh viện tỉnh khu vực miền Bắc (2009 - 2010)", Y học lẩm sàng, sổ 52 (tháng $5 / 2010)$, tr. 16 - 23.

\title{
THỰC TRẠNG KIẾN THỨC, THÁI Độ VỀ COVID-19 CỦA SINH VIÊN ĐIỀU DƯ ỚNG TRƯỜ'NG CAO ĐẲNG Y TẾ HÀ NỘI NĂM 2020
}

\author{
Trần Thị Nguyệt ${ }^{1}$, Trần Quỳnh Anh ${ }^{2}$, Nguyễn Thị Nguyệt ${ }^{4}$, \\ Bùi Văn Tùng ${ }^{2}$, Nguyễn Thị Hoa Huyền ${ }^{3}$
}

\section{TÓM TẮT}

Mục tiêu: Mô tả kiến thức, thái độ của sinh viên Điều dưỡng trường Cao đằng Y tế Hà Nội về Covid-19 năm 2020. Đối tượng và phương pháp nghiên cứu: Nghiên cứu mô tả cắt ngang được thực hiện trên 597 sinh viên điêu dưỡng trường Cao đẳng $Y$ tế Hà Nội. Kết quả: Điểm trung bình cho kiến thức, thái độ là $9,3 \pm 1,7$ và $44,8 \pm 7,2$. Phần lớn sinh viên có kiến thức đúng về tác nhân gây bệnh $(85,4 \%)$, đường truyền bệnh $(99,0 \%)$, thời gian ủ bệnh $(89,1 \%)$ và mang phương tiện phòng hộ cá nhân $(89,0 \%)$. Về thái độ của sinh viên, hâu hết sinh viên đều có thái độ tích cực về COVID-19, bên cạnh đó có môtt tỷ lệ đáng kể có thái độ tiêu cực về nguy cơ lây nhiếm cho bản thân $(30,4 \%)$ và gia đình $(28,2 \%)$. Điểm kiến thức và thái độ có sự khác biệt giữa giới tính, nguồn thông tin về COVID-19 được cung cấp từ Bộ Y tế/trường đại họccao đẳng/ người thân/bạn bè $(p<0,05)$. Kết luận: Nói chung, tỷ lệ sinh viên điều dưỡng có kiến thức tốt về COVID-19 khá cao; trong đó, tỷ lệ có kiến thức chưa

\footnotetext{
${ }^{1}$ Trường Cao đẳng Y tế Hà Nội;

2Viện đào tạo Y họ dự phòng và Y tế công cộng, Trường Đai học Y Hà Nối

${ }^{3}$ Viện Khoa học Sức khỏe, Trường Đại học VinUni;

${ }^{4}$ Đai hoc Y Dướ-Đai hoc Quốc Gia Hà Nôi.

Chịu trách nhiệm chính: Trân Thị Nguyệt

Email: tranthinguyet1402@gmail.com

Ngày nhận bài: 8.7.2021

Ngày phản biên khoa học: 3.9.2021

Ngày duyệt băi: 13.9.2021
}

đúng còn gặp nhiều ở các câu hỏi liên quan đến điều trị, các triệu chứng về COVID-19 và hệ thống dự phòng bệnh tại Việt Nam, đa phần sinh viên đã có thái độ tích cực về COViD-19. Các khía cạnh kiến thức nêu trền, giới tính và nguồn thông tin về COVID-19 cần được xem xét khi thực hiện các khóa đào tạo về sức khỏe cộng đồng cho sinh viên.

Tư khóa: COVID-19, kiến thức, thái độ, sinh viên Điều dưỡng

\section{SUMMARY}

\section{LEVELS OF KNOWLEDGE AND ATTITUDE ABOUT COVID-19 OF NURSING STUDENTS AT HANOI MEDICAL COLLEGES, 2020}

Objective: To describe levels of knowledge and attitudes of nursing students at Hanoi Medical College about Covid-19. Methods and subjects: A crosssectional descriptive study was conducted on 597 nursing students at Hanoi Medical College. Results: The average score for knowledge and attitude were $9.3 \pm 1.7$ and $44.8 \pm 7.2$, respectively. Majority of the study's participants had correct knowledge about pathogens $(85.4 \%)$, transmission route $(99.0 \%)$, incubation period ( $89.1 \%)$ and wearing personal protective equipment (89.0\%). Regarding students' attitudes, most students had a positive attitude about COVID-19, besides a significant proportion of the participants had a negative attitude about the risk of self-infection $(30.4 \%)$ and family $(28.2 \%)$. There were significant differences in knowledge and attitude scores between genders, sources of information about COVID-19 from the Ministry of Health/universities and 